\title{
Impact of Operating Conditions on Fouling Probability and Cake Height in Ultrafiltration of Latex Solution
}

\author{
Amira Abdelrasoul ${ }^{*}$, Huu Doan and Ali Lohi
}

\author{
Department of Chemical Engineering, Ryerson University, 350 Victoria Street, Toronto, Ontario M5B 2K3, \\ Canada
}

\begin{abstract}
The aim of the present study was to investigate the effects of operating conditions (transmembrane pressure, feed flow rate, and feed concentration) on the fouling attachment probabilities, mass of fouling, and cake height. Polycarbonate flat membrane with a pore size of $0.05 \mu \mathrm{m}$ was used under a constant feed flow rate and cross-flow mode in ultrafiltration of a latex paint solution. The results obtained indicate that increasing transmembrane pressure from 15 to $45 \mathrm{psi}$ lead to an increase in the particle-to-particle $\left(\alpha_{\mathrm{pp}}\right)$ and particle-to-membrane $\left(\alpha_{\mathrm{pm}}\right)$ attachment probabilities from 0.4 to 0.76 and 0.55 to 0.8 , respectively. It was observed that both attachment probabilities were significantly decreased when the feed flow rate was increased from 1 to 6 LPM (cross flow velocity from 10.4 to $62.5 \mathrm{~cm} / \mathrm{s}$ ). As a consequence, mass of fouling and cake height were reduced. Increasing the feed concentration from 0.78 to $1.82 \mathrm{~kg} / \mathrm{m}^{3}$ resulted in a substantial raise in the cake height from 4.3 to $18.5 \mu \mathrm{m}$. Response Surface Methodology (RSM) was used to set up the experimental design. According to regression analysis, two correlation models were obtained in order to predict the fouling attachment probabilities at different operation conditions. Estimated attachment probabilities were used to predict mass of fouling retained by membrane.
\end{abstract}

Keyword: Fouling, attachment, deposition, coagulation, cake.

\section{INTRODUCTION}

During the manufacturing of paint products, the cleaning of reactors and mixing basins generates a large amount of wastewater. Paint effluents typically have high levels of biological oxygen demand (i.e., BOD of greater than $580 \mathrm{mg} / \mathrm{L}$ ), chemical oxygen demand (COD, greater than $5500 \mathrm{mg} / \mathrm{L}$ ), and a high level of suspended solids and turbidity [1]. One of the benefits of treating the water-based paint effluent with UF over other processes, such as, electrochemical oxidation [2] or Fenton oxidation [3], is the potential to reclaim recovered solids from the paint effluent for recycling purposes, and reuse the permeate as processed or cleaning water [1]. One of the key factors that prevents a widespread application of UF is the decline of permeate flux with filtration time and the following loss of productivity due to membrane fouling during filtration process $[4,5]$.

Membrane fouling is one of the primary operational concerns of membrane applications. Membrane fouling reduces production rate and increases complexity of membrane filtration operation, since the system has to be halted more frequently to restore flux by backwashing. Membrane fouling leads to a significant increase in hydraulic resistance, manifested as the decline in permeate flux or increase in TMP, when the process is operated under constant-TMP or constant-

*Address correspondence to this author at the Department of Chemical Engineering, Ryerson University, 350 Victoria Street, Toronto, Ontario M5B 2K3, Canada; Tel: +1 647929 3491; Fax: +1 416979 5083;

E-mail: amira.abdelrasoul@ryerson.ca flux conditions, respectively. In a system where the permeate flux is maintained by increasing TMP, the energy required to achieve filtration escalates and causes higher power consumption. Notably, over a long period of operational time, membrane fouling is not completely reversible by back-washing [6]. In fact, fouling leads to a higher operational cost, higher energy demand, reduced membrane lifetime, and increased cleaning/washing frequency. In sea-water desalination plant the cost of the membrane unit is about $20-25 \%$ of the total capital cost. Usually about $10 \%$ of the membrane system is replaced annually in order to maintain the targeted product quality and quantity [7]. For a plant capable of producing 100 $\mathrm{m}^{3} /$ day, the energy consumption is more than 10 $\mathrm{KWh} / \mathrm{m}^{3}$, which can be reduced to $3.5 \mathrm{KWh} / \mathrm{m}^{3}$ if fouling is being controlled [8]. Therefore, novel techniques for the reduction and prevention of membrane fouling are necessary for future membrane development and application. Although some mechanisms involved in membrane fouling have been already proposed, the effects of operating parameters are yet to be fully understood.

Several empirical and semi-empirical models have been developed and reported in literature. Among them the most popular ones are the resistance-in-series model and the concentration polarization model based on the solute diffusion transfer [9-11]. One-dimensional and two-dimensional models for the permeate flux, derived from equations of continuity and motion, were also reported in the literature [12, 13]. Those models are system-specific and, hence, are limited in their 
process generalization and scale-up. In addition, monodispersed suspensions (solutions with single-size particles) were implemented in many of the reported studies. This raises certain limitations when it comes to the application of the results to actual wastewaters where suspended solids usually have a wide range of particle size distribution.

A mathematical model was developed in our previous work for ultrafiltration process [14]. This model was developed based on the analyses of the particle attachments. The model was combined with the Hermia model in order to further develop models for transmembrane pressure prediction. The resulting model could predict the mass of fouling retained by the membrane and the increase in the transmembrane pressure. The model equations are functions of the particle-to-particle attachment probability and the particle-to-membrane attachment probability. However, the effect of the operating parameters on the membrane fouling attachment probabilities was not fully investigated. Therefore, the objective of this study was to investigate the influence of operating conditions on the fouling probability and cake height. Predictive correlations for the calculation of the attachment fouling probabilities at a given operating conditions were also obtained. These attachment probabilities can be used to predict the mass of fouling retained by the membrane in the ultrafiltration of latex solution. Overall, this study provided a detailed analysis of the influence of the operating conditions on fouling attachment probabilities, mass of fouling, and the cake height.

\section{MEMBRANE FOULING AND ATTACHMENT PROBABILITIES}

A mathematical model was developed in our previous work for ultrafiltration of latex paint solution to describe the mechanism of membrane fouling phenomenon [14]. Fouling was considered primarily due to the attachments among foulant entities (coagulation attachment) and between foulants and membrane surfaces (depositional attachment). The coagulation attachment is the particle-to-particle attachment $\left(\alpha_{\mathrm{pp}}\right)$ and the depositional attachment is the particle-to-membrane attachment $\left(\alpha_{\mathrm{pm}}\right)$. Notably, the two attachment probabilities are dependent on both, the properties of the foulants and the membranes, and the solution chemistry and the operating conditions. Based on these mathematical model expressions [14], the mass of particles contributing to pore blocking can be calculated from
Equation (1). The mass of particles accountable to the cake layer can be calculated from Equation (2). These equations are functions of membrane physical properties, particle projected area, feed concentration, volumetric permeate flux, and attachment fouling probabilities. Summation of $m_{p}$ and $m_{c}$ represents the total mass of fouling retained by membrane $\left(m_{t}\right)$.

$$
\begin{aligned}
& m_{p}=\frac{\alpha_{\mathrm{pm}} \varepsilon_{\mathrm{s}}}{4^{\alpha \mathrm{pp}} \sigma_{\mathrm{L}}}\left[1-\exp \left(-4^{\alpha \mathrm{pp}} \sigma_{\mathrm{L}} \mathrm{C}_{\mathrm{in}} V_{s}\right)\right]+\frac{\alpha_{\mathrm{pm}} \varepsilon_{\mathrm{s}}}{\sigma_{\mathrm{s}}} \\
& {\left[1-\exp \left(-\sigma_{\mathrm{s}} \mathrm{C}_{\mathrm{in}} V_{s}\right)\right]+\frac{N_{m}}{\sigma_{\mathrm{xs}} \alpha_{\mathrm{pm}} B}\left\{\pi D_{m} L_{m} B \alpha_{\mathrm{pm}}\right.} \\
& -\ln \left[1+\exp \left(\pi D_{m} L_{m} B \alpha_{\mathrm{pm}}-\frac{\sigma_{\mathrm{xs}} \alpha_{\mathrm{pm}} B}{N_{m}} \mathrm{C}_{\mathrm{in}} V_{s}\right)\right] \\
& m_{c}=\alpha_{\mathrm{pp}} \mathrm{C}_{\mathrm{in}} V_{s}+\left\{\frac{\alpha_{\mathrm{pm}}\left(1-\varepsilon_{\mathrm{s}}\right)-\alpha_{\mathrm{pp}}}{4^{\alpha \mathrm{pp}}}\right. \\
& {\left[\frac{\left[1-\exp \left(-4^{\alpha \mathrm{pp}} \sigma_{\mathrm{L}} \mathrm{C}_{\mathrm{in}} V_{s}\right)\right]}{\sigma_{\mathrm{L}}}+\right.} \\
& \left.\left.\frac{\left[1-\exp \left(-4^{\alpha \mathrm{pp}} \sigma_{\mathrm{s}} \mathrm{C}_{\mathrm{in}} V_{s}\right)\right]}{\sigma_{\mathrm{s}}}\right]\right\}
\end{aligned}
$$

where $m_{p}\left[\mathrm{~kg} / \mathrm{m}^{2}\right]$ is the total mass of particles attached to membrane pores per unit membrane surface area, $m_{c}\left[\mathrm{~kg} / \mathrm{m}^{2}\right]$ is the total mass of particles in the cake layer per unit membrane surface area, $\varepsilon_{\mathrm{s}}$ [dimensionless] is the membrane surface porosity, $\sigma_{L}$ $\left[\mathrm{m}^{2} / \mathrm{kg}\right]$ is the projected area of a unit mass of the large particles (particle diameter $\geq$ pore diameter) on membrane surface, $\sigma_{\mathrm{s}}\left[\mathrm{m}^{2} / \mathrm{kg}\right]$ is the projected area of a unit mass of the small particles on membrane surface (pore diameter 6 < particle size < pore diameter $/ 2), \sigma_{\mathrm{xs}}\left[\mathrm{m}^{2} / \mathrm{kg}\right]$ is the projected area of a unit mass of the very small particles on membrane surface (particle size < pore diameter/6), $N_{m}$ is the number density of membrane pores per unit membrane surface area, $L_{m}[\mathrm{~m}]$ is the length of a membrane pore, $D_{m}[\mathrm{~m}]$ is the membrane pore diameter, $B\left[\mathrm{~m}^{-2}\right]$ is the mass transfer coefficient, $C_{i n}\left[\mathrm{~kg} / \mathrm{m}^{3}\right]$ is the mass concentration of particles at the inlet of a membrane pores and $V_{s}\left[\mathrm{~m}^{3} / \mathrm{m}^{2}\right]$ is the cumulative volume of the permeate normalized to membrane surface area.

Equations (1) and (2) are solved for $\alpha_{\mathrm{pp}}$ and $\alpha_{\mathrm{pm}}$ using $m_{p}$ and $m_{c}$ values measured experimentally, as described in section (3.1). Also, the Response Surface Methodology (RSM) was used to design experiments that provided sufficient data to establish correlations for the prediction of the attachment fouling probabilities at a given operational condition. These correlations can be then used with our previous mathematical model to 


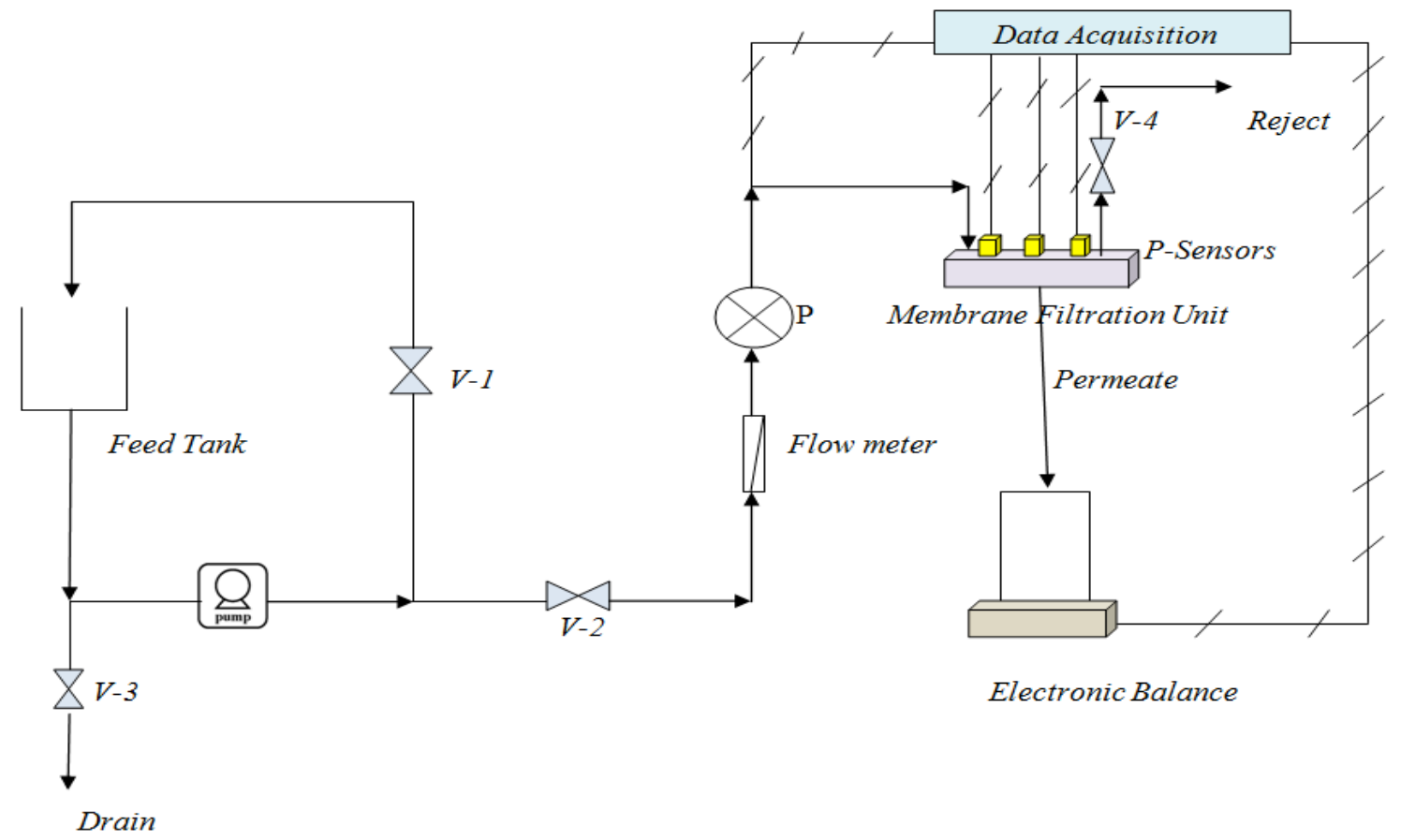

Figure 1: Schematic diagram of experimental set-up.

make a complete set of predictive models. The predicted fouling attachment probabilities from the correlations could be used to calculate the total mass of fouling retained by the membrane from Equation (1) \& (2). Furthermore, irreversible fouling after backwash, increase in transmembrane pressure through the filtration process, and the increase in transmembrane pressure due to irreversible fouling can all be estimated using these mathematical expressions, as illustrated in our previous work [14].

\section{MATERIALS \& METHODS}

\subsection{Experimental Set-Up and Procedure}

A schematic diagram of the experimental setup is shown in Figure 1. It includes a $1.0 \mathrm{hp}$ feed pump and a flow meter (Model F-400N, Blue White Industries Ltd., USA) ranging from 0.0 to $7.0 \mathrm{~L} / \mathrm{min}$. Monitoring of the pressure is accomplished by using a pressure transducer (Model V82/V182/V782, George Fischer,
USA). Three pressure sensors (0-100 PSI) (Model Omega PX303-100G5V, $\pm 0.25 \%$ ) connected to the data acquisition system to measure the pressure in the filtration unit and to evaluate the pressure influence on cake layer thickness. The permeate stream is continuously measured gravimetrically using an electronic balance (Model Adventurer Pro AV2101, Ohaus Corporation, New Jersey, USA, $\pm 0.1 \mathrm{~g}$ ). Both the pressure transducer and the electronic balance are connected to a data acquisition system. The membrane filtration unit is constructed from two acrylic plates held together by system of nuts and bolts. There were 2 rectangular slits, one on each end of the unit, for the feed inlet and the reject outlet respectively. The membrane sheet area was $28 \mathrm{~cm} \times 8 \mathrm{~cm}$ and was further supported by a porous stainless steel disc. For this experiment, Polycarbonate membranes with nominal pore sizes of $0.05 \mu \mathrm{m}$ (GE Water \& Process Technologies) were used. Table 1 shows the membrane characteristics which is hydrophilic with a

\section{Table 1: Properties of GE Membranes}

\begin{tabular}{|c|c|c|c|c|}
\hline $\begin{array}{c}\text { Pore size } \\
\boldsymbol{\mu m}\end{array}$ & $\begin{array}{c}\text { Pore Density } \\
\left(\text { pore } / \mathbf{c m}^{\mathbf{2}}\right)\end{array}$ & $\begin{array}{c}\text { Nominal weight } \\
\left(\mathbf{m g} / \mathbf{c m}^{2}\right)\end{array}$ & $\begin{array}{c}\text { Nominal Thickness } \\
\boldsymbol{\mu m}\end{array}$ & $\begin{array}{c}\text { Typical flow rate }^{\mathrm{d}} \\
\mathbf{m L} / \mathbf{m i n} / \mathbf{c m}^{2}\end{array}$ \\
\hline \hline 0.05 & $6 \times 10^{8}$ & 0.7 & 6 & 0.4 \\
\hline
\end{tabular}

Notes:

${ }^{\mathrm{a}}$ Tolerance $+0 \%,-20 \%$

${ }^{\mathrm{b}}$ Tolerance $\pm 15 \%$.

${ }^{\mathrm{c}}$ Tolerance $\pm 10 \%$.

${ }^{d}$ Initial flow rates measured using pre-filtered water at 10 PSI. 
narrow pore size distribution. The gap between the two plates for the liquid flow was $2 \mathrm{~mm}$. O-rings were used to seal the two plates of the unit.

In a feed tank a measured volume of latex paint (Type: Glidden Easyflow Interior Latex Paint, White, Flat) was mixed with distilled water to get a solution of a specific feed solid concentration. Although, vinyl acrylic latex was used as the binder in the paint, the exact composition of the paint is proprietary. Latex solution $\mathrm{pH}$ and its density were 9.0 and $1.34 \mathrm{~kg} / \mathrm{L}$, respectively. The volume of latex paint used varied depending on the solid concentration required. For example, in order to obtain a feed solid concentration of $0.13 \%$ by weight, $2.5 \mathrm{ml}$ of latex paint was used for each liter of solution. Lastly, during the experiments, distilled water was used for the preparation of the feed.

For each experimental run, membrane sheet was placed in the membrane filtration unit. The feed tank was then filled with a latex paint solution at a specific solid concentration. The solution was mixed in the tank via the recycle line by fully opening the valve $\mathrm{V}-1$ and closing V-2 and V-3. At the beginning of the experimental run, the feed valve $\mathrm{V}-2$ and the reject valve V-4 were opened slowly in order to set the pressure and the flow rate to appropriate values. If high pressure was necessary, the reject valve $\mathrm{V}-4$ was opened less than would be required for lower operating pressures at the same feed flow rate, while the feed valve V-2 was opened slightly more. The reject stream is not returned to the feed tank to have a steady sate filtration with a specific feed concentration. Measurements of the pressure of the stream entering the filtration unit was displayed on a computer monitor and recorded at one second intervals. The permeate steam was collected on an electronic balance. This electronic balance was also connected to the data acquisition for accurate and automatic recording of the permeate mass as it was collected over time.

The total mass of fouling $\left(m_{t}\right)$ is the difference in weight of the membrane before and after filtration. For the measurement of the mass of particles contributing to cake layer $\left(m_{c}\right)$, the cake was removed (scratched off) under the microscope, so as to keep the membranes pores blocked with the particles contribute to the pore blocking. The scratched off solid portion was then weighted to determine the amount of the cake layer. The blocked pores of the membrane were checked using SEM. For the measurement of the mass of particles contributing to pore blocking $\left(m_{p}\right)$, it was the difference in the weight of the membrane before filtration (clean membrane) and the weight after the scratched off the cake layer. The mass of particles $(\mathrm{mt}$, $m_{c}$ and $m_{p}$ ) was measured using an electronic balance (Mettler Toledo Model AB 54-S Fact, Switzerland, \pm 0.1 $\mathrm{mg}$ ).

\subsection{Experimental Design}

The main operational process parameters investigated for the membrane ultrafiltration process are the transmembrane pressure, feed flow rate, and feed concentration.

The temperature of the solution was kept at room temperature $\left(22-24{ }^{\circ} \mathrm{C}\right)$. Operation time for each experiment was kept constant for each of the experimental runs in order to investigate the influence of the operating conditions on mass of particles retained by membrane, permeate flux, fouling probabilities, and cake height. Ranges of the operating conditions are shown in Table 2.

Table 2: Process Parameters Level

\begin{tabular}{|c|c|c|c|c|}
\hline \multirow{2}{*}{ Factor } & \multirow{2}{*}{ Variable } & \multicolumn{2}{|c|}{ Range } & \multirow{2}{*}{ Unit } \\
\cline { 3 - 4 } & & Low & High & \multirow{2}{*}{} \\
\cline { 3 - 4 } & & $\mathbf{( - 1 )}$ & $\mathbf{( 1 )}$ & \\
\hline \hline A & Pressure & 15 & 35 & $\mathrm{psi}$ \\
\hline B & Feed Flow rate & 1 & 7 & $\mathrm{LPM}$ \\
\hline C & Feed concentration & 0.78 & 1.82 & $\mathrm{~kg} / \mathrm{m}^{3}$ \\
\hline
\end{tabular}

In this study, the Central Composite Face-Centered CCF Response Surface Method (RSM) was selected as the experimental design method [15]. Fouling probabilities $\left(\alpha_{p p}\right.$ and $\left.\alpha_{p m}\right)$ are the main responses. The process parameters include transmembrane pressure, feed flow rate, and feed concentration. Table $\mathbf{3}$ presents coded and actual levels of the process parameters. The coded values are designated as -1 (low), 0 (medium), and 1 (high). Twenty experiments were performed and their results were then analyzed using multi-regression. For the minimization of error, six replicated experiments at zero code for each process parameter were performed in randomized order. A statistical software (Stat-Ease, Version 8.0 Stat-Ease Inc., USA) was used to determine the bestfitting model by regression and stepwise elimination. Coefficients of a full model were evaluated by regression analysis and tested for their significance. The significance of the coefficients was assessed by Ftest, and the insignificant coefficients were excluded. Pvalue was used to set the level of confidence for the $\mathrm{F}$ - 
test. The model fitting was evaluated by the coefficients of determination $\left(R^{2}\right)$ and the analysis of variances (ANOVA). Stat-Ease software was further used to identify the process parameters for the ultrafiltration fouling of latex solution that have minimum fouling attachment probabilities.

The quadratic model and linear model can be expressed as Equations (3) and (4) below:

$$
\begin{aligned}
& Y=\beta_{k o}+\sum_{i=1}^{3} \beta_{k i} x_{i}+\sum_{i=1}^{3} \beta_{k i i} x_{i}^{2}+\sum_{i=1}^{3} \sum_{j=i+1}^{3} \beta_{k i j} x_{i} x_{j} \\
& Y=\beta_{k o}+\sum_{i=1}^{3} \beta_{k i} x_{i}
\end{aligned}
$$

where $Y$ is the response factor of attachment probabilities $\left(\alpha_{\mathrm{pp}} \& \alpha_{\mathrm{pm}}\right), x_{\mathrm{i}}$ the $\mathrm{i}^{\text {th }}$ independent factor, $\beta_{k o}$ the intercept, $\beta_{k i}$ the first-order model coefficients, $\beta_{k i i}$ the quadratic coefficients for the factor $\mathrm{i}$, and $\beta_{k i j}$ is the linear model coefficient for the interaction between factors $\mathrm{i}$ and $\mathrm{j}$.

\subsection{Analytical Methods}

\subsubsection{Solid Content}

Samples of the feed and the permeate streams were collected during each experimental run. A measured mass of each sample was then transferred to a metal dish that was placed in an oven at $105^{\circ} \mathrm{C}$ for the duration of a week. The mass of each dish was periodically measured, approximately every three days, until there was no discernible change. From the measured masses of the solution and the solid in each metal dish, the solid content of the paint solution was then determined.

\subsubsection{Particle Size Distribution of Latex Paint Dispersions}

The particle size distribution of the latex paint solution was determined using a particle size analyzer (Model 2000 -Malvern Mastersizer) which had a range of 0.02 to 2000 microns. The particle size distribution of the latex solution which had a range of 0.03 to 800 microns is illustrated in Figure 2. The concentration of samples did not affect the particle size distribution obtained during this experiment.

\subsubsection{Scanning Electron Microscopy Imaging}

In order to obtain surface images of the membrane before and after filtration, a scanning electron microscope (Model JEOL, JSM-6380 LV, Oxford Instrument, and U.K.) was used. A clean membrane sample was coated with a thin layer of gold particles to improve the resolution of the images. Figure 3 show that the surface of the membrane had a high pore density, while the pores had a random distribution arrangement. The measurement of the dimensions of the pore openings indicated that the majority of the pores were approximately $0.05 \mu \mathrm{m}$ and thus constituted the average used in the model calculations of this study.

\section{RESULTS \& DISCUSSION}

\subsection{Effect of Operating Conditions on Fouling Probabilities and the Cake Layer}

One of the objectives of the present study was to investigate the impact of operating conditions on fouling attachment probabilities, the mass of fouling

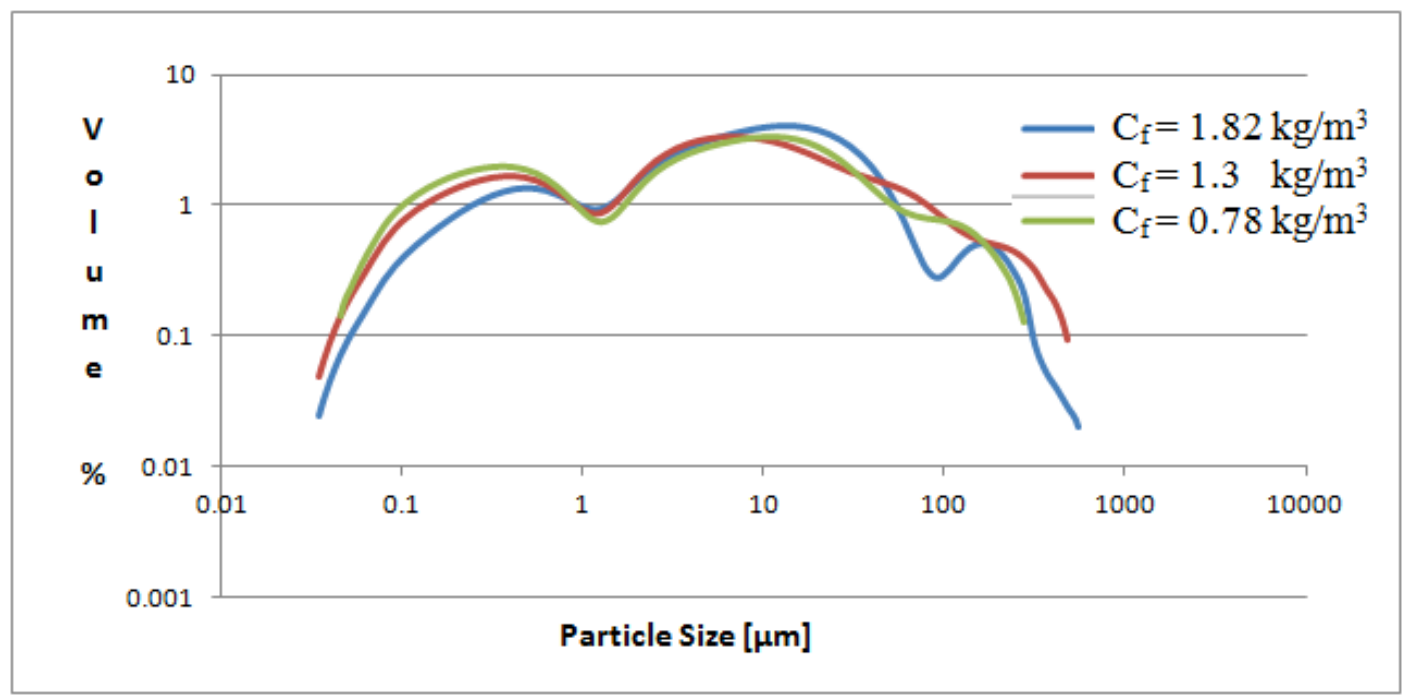

Figure 2: Particles size distribution of feed samples at different concentrations. 
and the cake layer. Results obtained show that the transmembrane pressure (TMP), feed flow rate and feed concentration had a significant effect on the fouling attachment probabilities, mass of fouling and cake height.

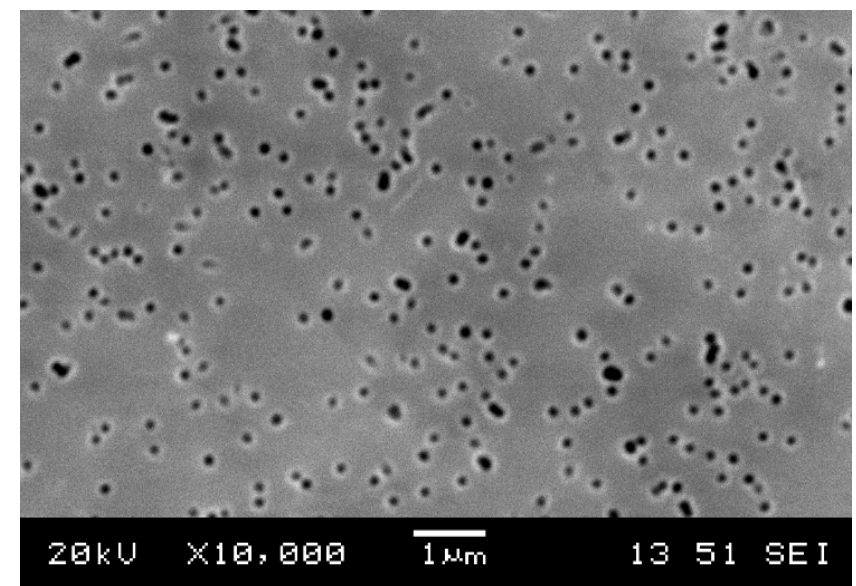

Figure 3: SEM image of clean membrane $0.05 \mu \mathrm{m}$, gold-coated.

\subsubsection{Effect of Pressure on Fouling Probabilities and the Cake Height}

At a feed flow rate of $4.0 \mathrm{~L} / \mathrm{min}$ and a feed concentration of $1.3 \mathrm{~kg} / \mathrm{m}^{3}$, increasing the transmembrane pressure from 15 to $45 \mathrm{psi}$ lead to increases in the particle-to-particle $\left(\alpha_{\mathrm{pp}}\right)$ and the particle-to-membrane $\left(\alpha_{\mathrm{pm}}\right)$ attachment probabilities from 0.4 to 0.76 and 0.55 to 0.8 , respectively. Higher fouling attachment probabilities resulted in an increase in the total mass of fouling from $0.0104 \mathrm{~kg} / \mathrm{m}^{2}$ to 0.0145 $\mathrm{kg} / \mathrm{m}^{2}$. As shown in Figure 4, when the pressure was raised from 15 to $35 \mathrm{psi}$, the fouling attachment probabilities increased from 0.4 to 0.75 and from 0.5 to 0.8 for coagulation attachment probability $\left(\alpha_{\mathrm{pp}}\right)$ and depositional attachment probability $\left(\alpha_{\mathrm{pm}}\right)$, respectively. However, further increase in pressure did not affect $\alpha_{p p}$ and $\alpha_{\mathrm{pm}}$ significantly. When the transmembrane pressure increased from 15 to $35 \mathrm{psi}$, the volumetric permeate flux and the mass of fouling increased from $0.0125 \mathrm{~m}^{3} / \mathrm{m}^{2}$ to $0.0178 \mathrm{~m}^{3} / \mathrm{m}^{2}$ and from $0.0104 \mathrm{~kg} / \mathrm{m}^{2}$ to $0.0142 \mathrm{~kg} / \mathrm{m}^{2}$, respectively. Higher permeate flow through the membrane brought more particles to the membrane's surface. Hence, chances for the particleto-particle and particle-to-membrane collision and attachment have increased, resulting in higher attachment probabilities. Notably, increasing the pressure from 35 to 45 psi resulted in an insignificant change in the volumetric permeate flux $\left(V_{s}\right)$ from $0.0178 \mathrm{~m}^{3} / \mathrm{m}^{2}$ to $0.0179 \mathrm{~m}^{3} / \mathrm{m}^{2}$. The reason for the minimal increase lies in the fact that the transmembrane pressure higher than the critical pressure has an insignificant effect on the permeate flux or the mass of fouling retained by the membrane. Thus, the fouling attachments probabilities values leveled off to a relatively constant value. Moreover, Figure 4 shows that the depositional attachment probability $\alpha_{p m}$ had higher values than the coagulation attachment probability $\alpha_{p p}$. This indicates that the transmembrane pressure might have more impact on the pore blocking and the membrane-to-particle attachment than the cake layer build up.

Figure 5 represents the SEM images of the membrane after the ultrafiltration experiment at different pressures, and at a fixed feed flow rate, filtration time and feed concentration, illustrating the

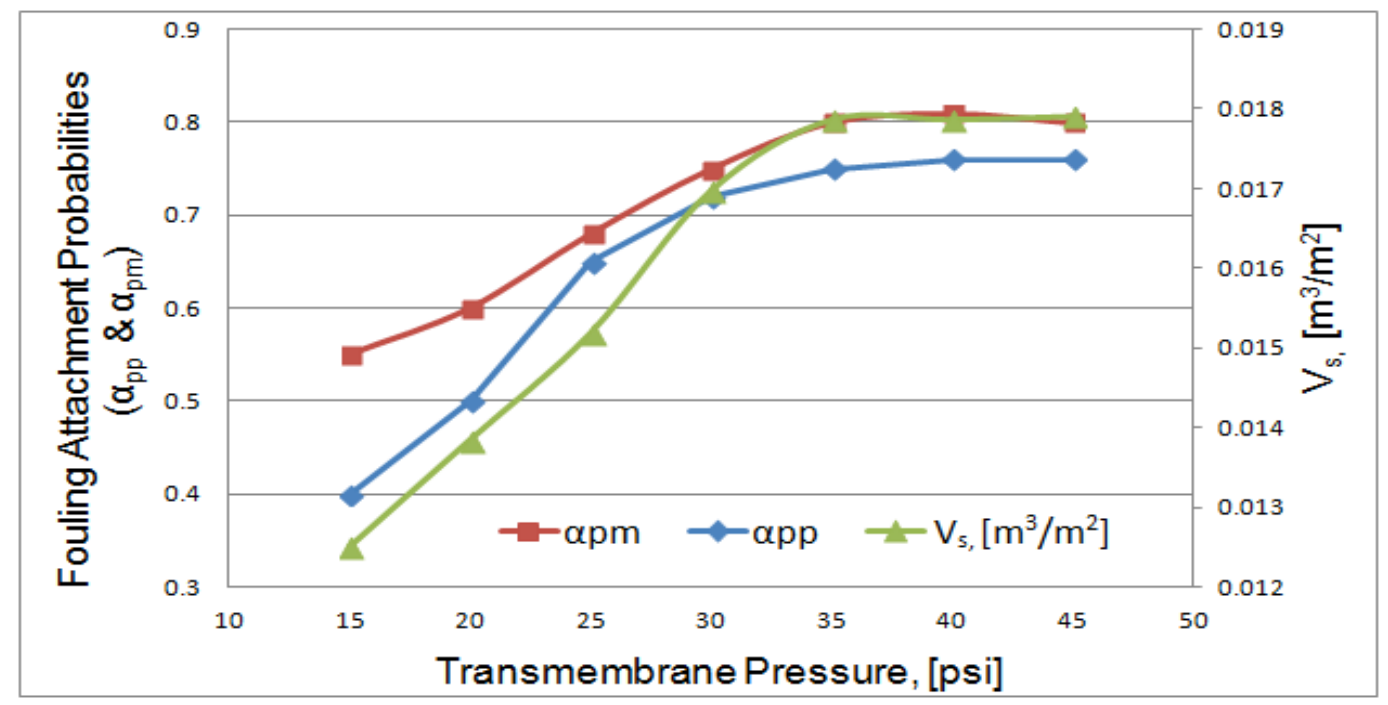

Figure 4: Effect of transmembrane pressure on fouling attachment probabilities $\left(\alpha_{\mathrm{pp}}, \alpha_{\mathrm{pm}}\right)$ and the volumetric permeate flux $\left(V_{s}\right)$ at $[Q=4 \mathrm{LPM}],\left[\mathrm{C}_{\mathrm{f}}=1.3 \mathrm{~kg} / \mathrm{m}^{3}\right]$. 


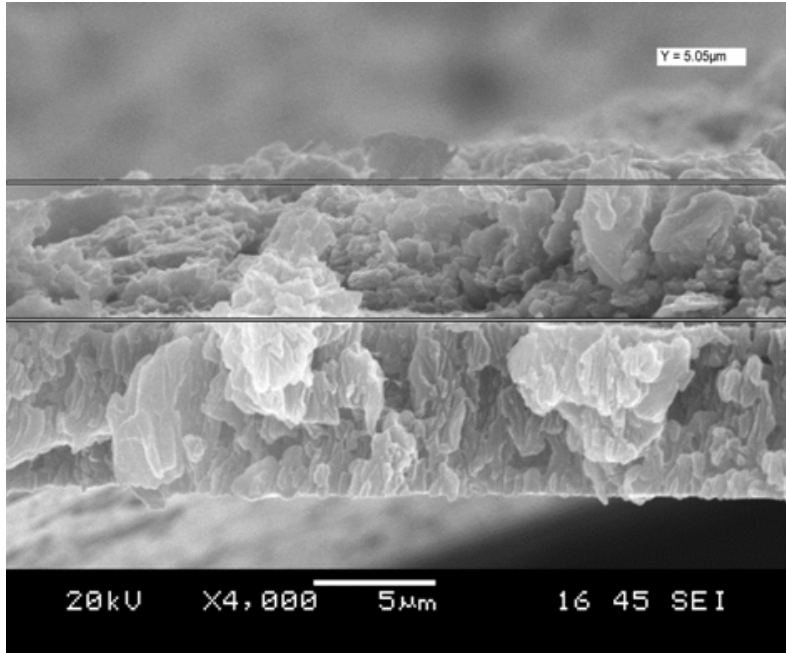

(a)

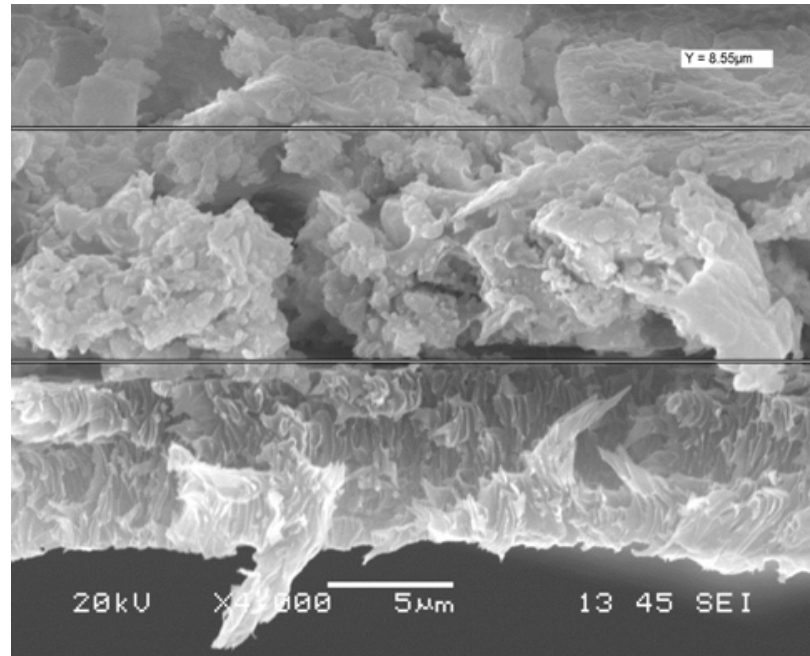

(b)

Figure 5: SEM images of membrane after ultrafiltration $[Q=4 L P M],\left[C_{f}=1.3 \mathrm{~kg} / \mathrm{m}^{3}\right]$. (a) Cake height $5.05 \mu \mathrm{m}$ at pressure $15 \mathrm{psi}$. (b) Cake height $8.55 \mu \mathrm{m}$ at pressure 35 psi.

effect of pressure on the cake build-up. Figure 5 a was obtained from a sample at a pressure of 15 psi, showing a thick cake sample (average thickness of about $5.05 \mu \mathrm{m})$. Figure $\mathbf{5 b}$ shows that the cake thickness increased to about $8.55 \mu \mathrm{m}$ when the pressure was increased to $35 \mathrm{psi}$. Arguably, at the transmembrane pressure of 35 psi (critical pressure at feed flow rate 4 LPM and feed concentration 1.3 $\mathrm{kg} / \mathrm{m}^{3}$ ), the concentration polarization might attain a sufficient level for the retained solutes at the membrane surface to reach the gel concentration. Once a gel layer has formed, further increase in the applied pressure does not lead to the increase in the volumetric permeate flux above the one attained at critical pressure value. However, higher pressure causes the formed cake layer on membrane surface to be compressed. As shown in Figure 6 the cake layer becomes compressed to $7.9 \mu \mathrm{m}$ at 45 psi.

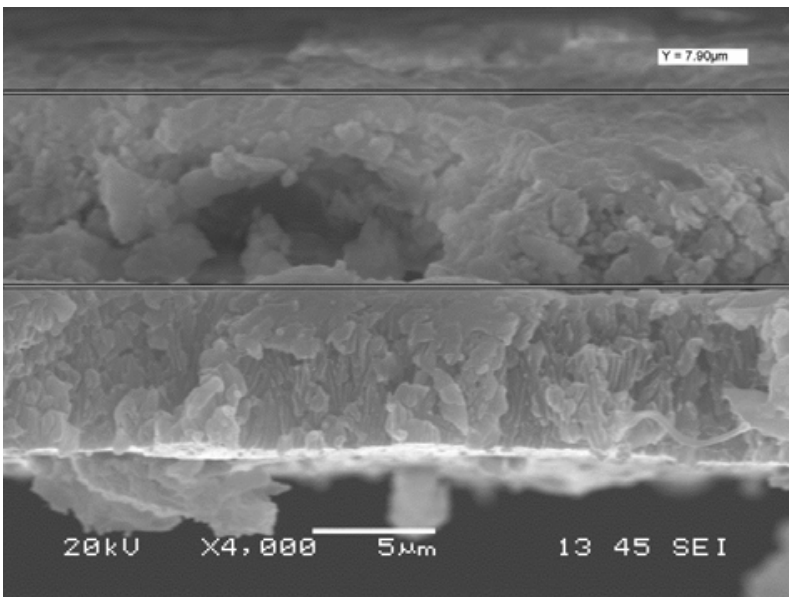

Figure 6: SEM image of membrane after UF at 45 psi, 4 LPM and $1.3 \mathrm{~kg} / \mathrm{m}^{3}$. (Cake height $\left.7.9 \mu \mathrm{m}\right)$.

\subsubsection{Effect of Feed Flow Rate on Fouling Probabilities and the Cake Height}

Figure 7 depicts the effect of the feed flow rate on the fouling attachment probability at $15 \mathrm{psi}$ and feed concentration at $1.3 \mathrm{~kg} / \mathrm{m}^{3}$. It was observed that the particle-to-particle attachment probability $\left(\alpha_{\mathrm{pp}}\right)$ was significantly reduced from 0.86 at 1 LPM to 0.19 at 6 LPM, while the particle-to-membrane attachment probability $\left(\alpha_{\mathrm{pm}}\right)$ decreased from 0.82 to 0.49 . The probable cause for this substantial reduction in $\alpha_{\mathrm{pp}}$ with the feed flow rate is that at a higher flow rate, a higher shear rate is applied on the particles at the cake layer. Consequently, a higher number of particles was washed away from the cake layer. In particular, as the feed flow rate was increased to 3.0 LPM, there was a stiff decrease in $\alpha_{p p}$, which, arguably, marks the critical flow rate for membrane fouling in this system. On the other hand, at higher flow rate, the cumulative permeate flux $\left(V_{s}\right)$ increased from 0.0076 to 0.014 $\mathrm{m}^{3} / \mathrm{m}^{2}$. As a result, more particles were brought into contact with the membrane, leading to an increase in collision and attachments between particles and membrane surface. Consequently, $a_{\mathrm{pm}}$ decreased at a lower rate as compared with that of $\alpha_{p p}$. As shown in Figure $7, \alpha_{p p}$ and $\alpha_{p m}$ approach maximum values at flow rate less than 1.0 LPM. It was also observed that as the fouling attachment probabilities decreased, the mass of particles retained by the membrane dropped from $0.0162 \mathrm{~kg} / \mathrm{m}^{2}$ at a feed low rate of $1 \mathrm{LPM}$ to $0.00838 \mathrm{~kg} / \mathrm{m}^{2}$ at $6 \mathrm{LPM}$. Particles accumulated on the membrane surface would be washed back to the bulk fluid more at higher flow rates; and thus, the concentration polarization effect diminished. This, in 


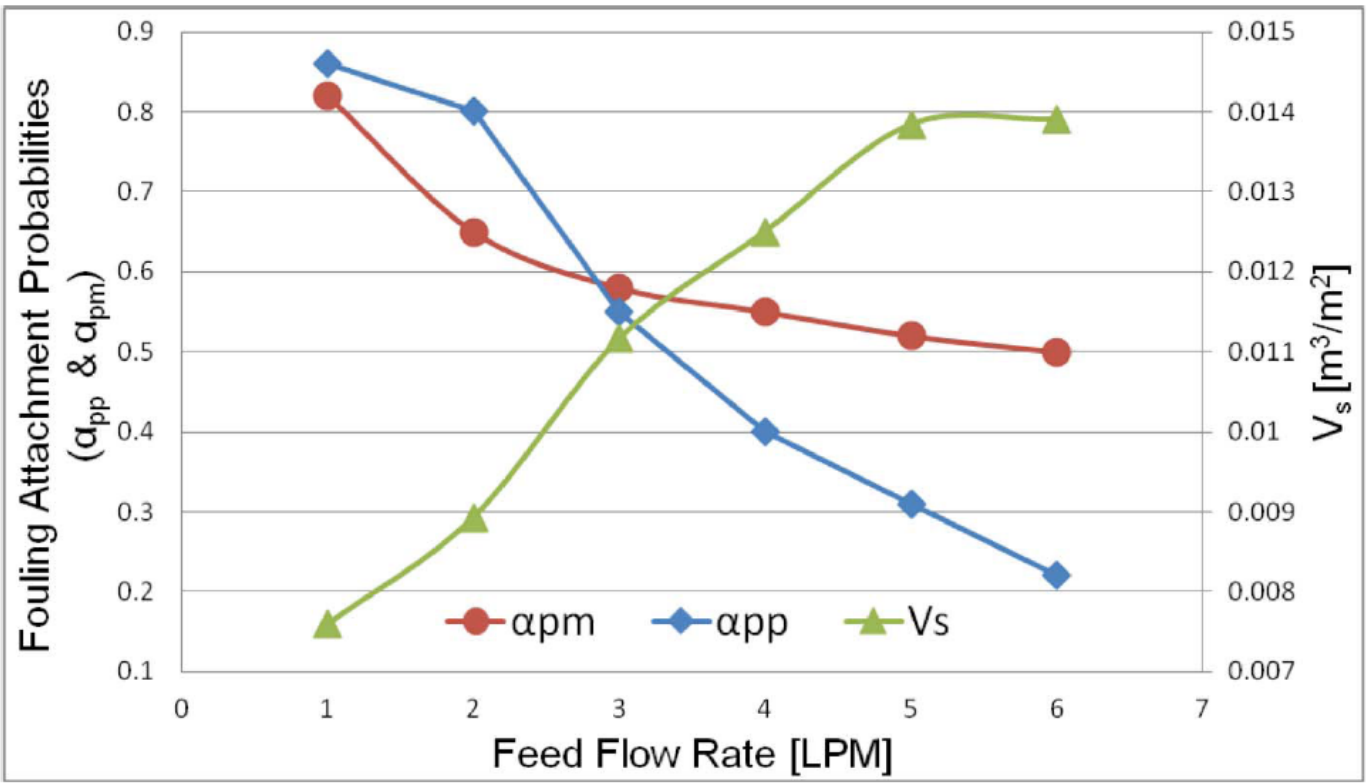

Figure 7: Effect of feed flow rate on fouling attachment probabilities $\left(\alpha_{\mathrm{pp}}, \alpha_{\mathrm{pm}}\right)$ and the volumetric permeate flux $\left(V_{s}\right)$ at $[P=15$ psi], $\left[C_{f}=1.3 \mathrm{~kg} / \mathrm{m}^{3}\right]$.

turn, caused the osmotic pressure to decrease, permeation flux to increase, and the solid retained and cake height to decrease.

Figure 8 presents the SEM images of the membrane after ultrafiltration at different feed flow rates (fixed pressure, filtration time, and feed concentration). Figure 8a was obtained from a sample at a feed flow rate of $1.0 \mathrm{~L} / \mathrm{min}$, showing the cake thickness of about $13.8 \mu \mathrm{m}$. Figure $\mathbf{8 b}$ shows that the cake thickness decreased to about $2.4 \mu \mathrm{m}$ at the feed flow rate of 6.0 $\mathrm{L} / \mathrm{min}$. The cross-flow of the feed can be considered as a continuous washing of the cake layer, and hence, the resultant particle-to-particle attachment $\left(\alpha_{\mathrm{pp}}\right)$ decreased from 0.86 at 1 LPM to 0.19 at 6 LPM.

\subsubsection{Effect of Feed Concentration on Fouling Probabilities and the Cake Height}

Figure 9 shows the effect of the feed concentration on the fouling attachment probability at a feed flow rate of $1 \mathrm{~L} / \mathrm{min}$ and $15 \mathrm{psi}$. Increasing the feed concentration from $0.78 \mathrm{~kg} / \mathrm{m}^{3}$ to $1.82 \mathrm{~kg} / \mathrm{m}^{3}$ resulted in a significant increase in the coagulation attachment probability, $\alpha_{p p}$, and a significant decrease in the depositional attachment probability, $a_{\mathrm{pm}}$. The particleto-particle attachment, $\alpha_{\mathrm{pp}}$, increased from 0.3 to 0.9 ,

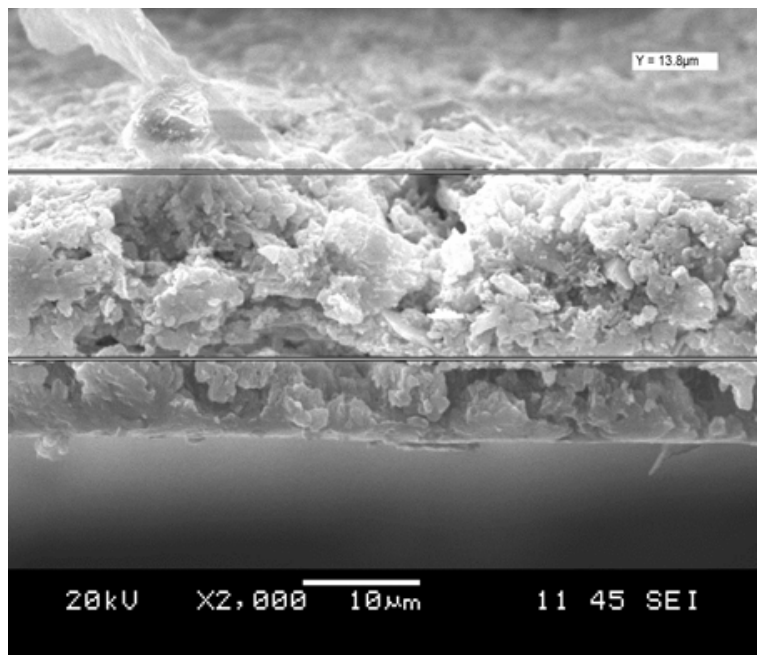

(a)

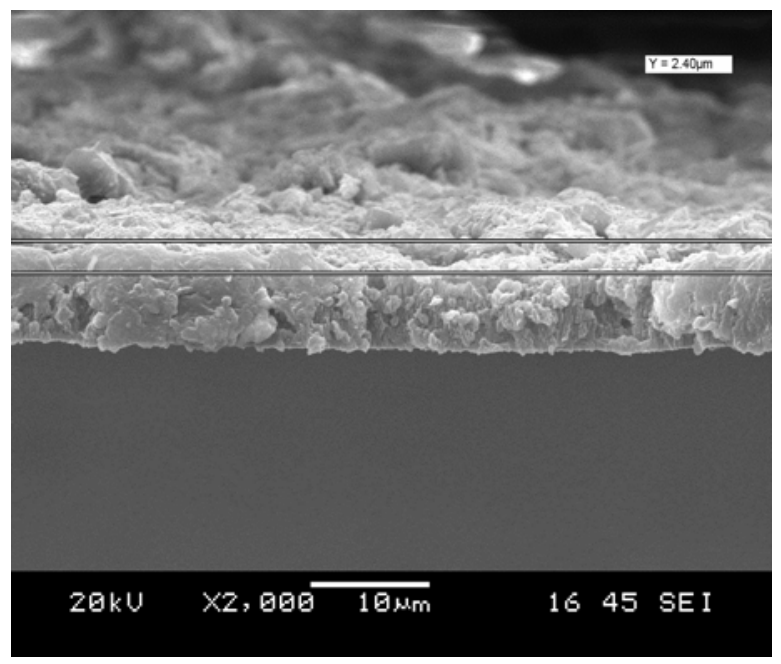

(b)

Figure 8: SEM images of membrane after ultrafiltration $[P=15 \mathrm{psi}],\left[\mathrm{C}_{f}=1.3 \mathrm{~kg} / \mathrm{m}^{3}\right]$. (a) Cake height $13.8 \mu \mathrm{m}$ at feed flow rate 1 LPM. (b) Cake height $2.4 \mu \mathrm{m}$ at feed flow rate 6 LPM. 


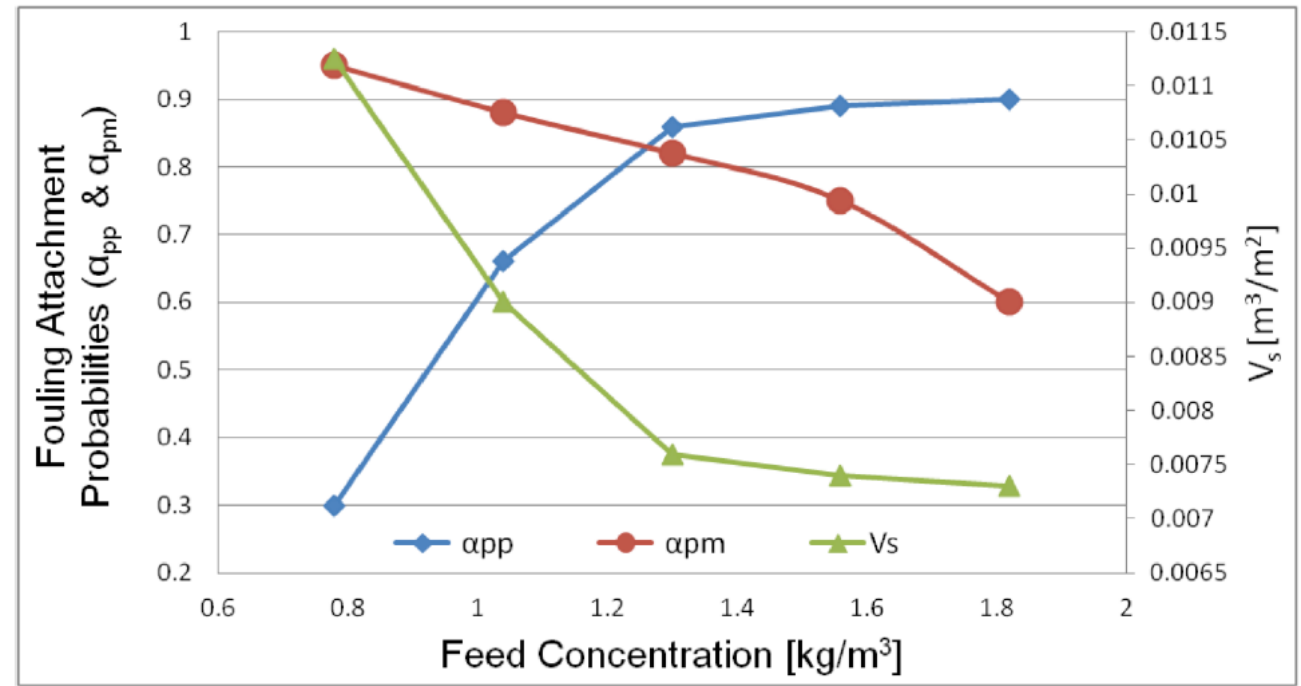

Figure 9: Effect of feed concentration on fouling attachment probabilities $\left(\alpha_{\mathrm{pp}}, \alpha_{\mathrm{pm}}\right)$ and the volumetric permeate flux $\left(V_{s}\right)$ at $[\mathrm{Q}=1$ LPM], [P=15 psi].

while the particle-to-membrane attachment, $\alpha_{\mathrm{pm}}$, decreased from 0.95 to 0.6 . Increasing the feed concentration resulted in a higher chance of particle-toparticle collision and attachment. As a consequence, the coagulation attachment probability and cake layer build up are enhanced. It was also observed that total mass of fouling was increased from $0.0088 \mathrm{~kg} / \mathrm{m}^{2}$ to $0.0133 \mathrm{~kg} / \mathrm{m}^{2}$ when the concentration increased from $0.78 \mathrm{~kg} / \mathrm{m}^{3}$ to $1.82 \mathrm{~kg} / \mathrm{m}^{3}$, as expected. On the other hand, increasing the feed concentration lead to decreases in the volumetric permeate flux $\left(V_{s}\right)$ from $0.011 \mathrm{~m}^{3} / \mathrm{m}^{2}$ to $0.007 \mathrm{~m}^{3} / \mathrm{m}^{2}$. A reduced permeates flow through the membrane pores resulted in a lower chance of particle-to-membrane collision and attachment. The depositional attachment probability, $\alpha_{\mathrm{pm}}$, thus decreased from 0.95 to 0.6 . Moreover, as Figure 10 illustrates, the feed concentration had a significant effect on the cake layer thickness. The cake thickness increased from $4.3 \mu \mathrm{m}$ to $18.5 \mu \mathrm{m}$ when the feed concentration was increased from $0.78 \mathrm{~kg} / \mathrm{m}^{3}$ to $1.82 \mathrm{~kg} / \mathrm{m}^{3}$. Therefore, it can be concluded that the particle-to-particle attachment probability $\left(\alpha_{p p}\right)$ was the predominant factor responsible for the cake formation, even though the particle-to-membrane attachment $\left(a_{\mathrm{pm}}\right)$ was decreased with the increase in the feed concentration.

\subsection{Statistical Analysis}

In order to minimize membrane fouling, this study focused on the investigation of the influences of the process parameters on the fouling attachment probabilities $\left(\alpha_{\mathrm{pp}}\right.$ and $\left.\alpha_{\mathrm{pm}}\right)$. The process parameters include transmembrane pressure, feed flow rate, and

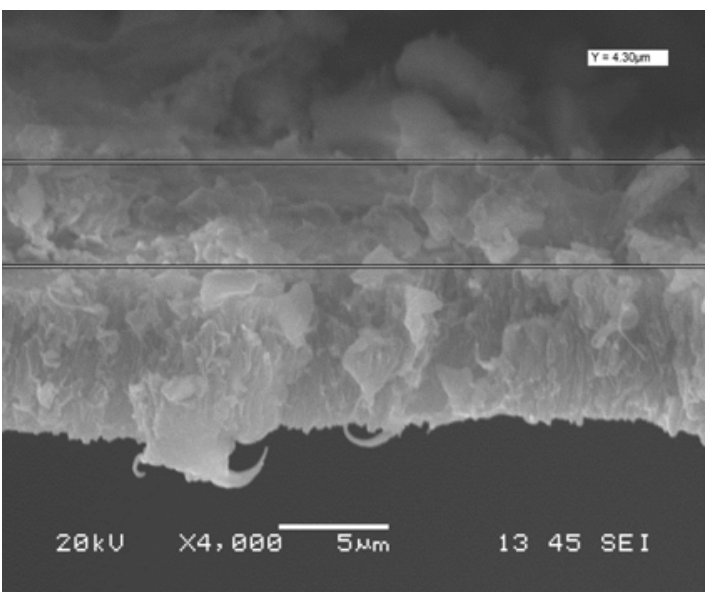

(a)

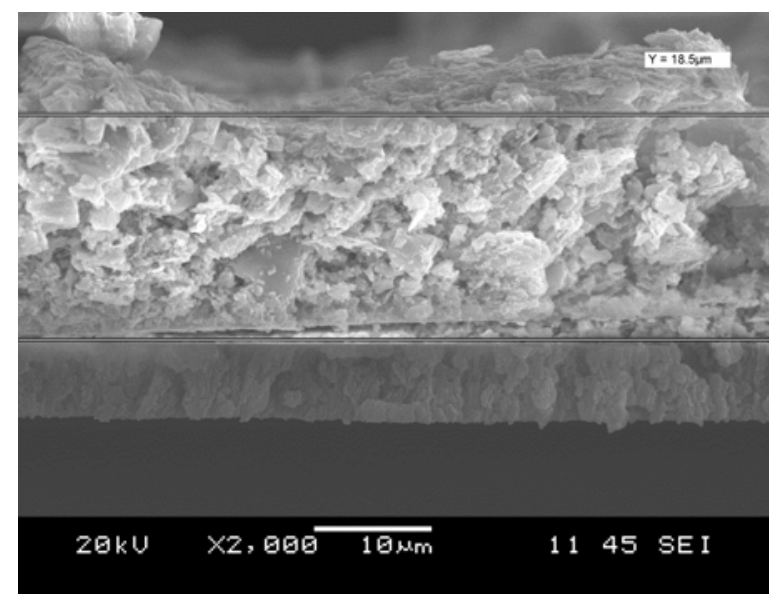

(b)

Figure 10: SEM images of membrane after ultrafiltration [Q=1 LPM], $[P=15$ psi]. (a) Cake height $4.3 \mu \mathrm{m}$ at feed concentration $0.78 \mathrm{~kg} / \mathrm{m}^{3}$. (b) Cake height $18.5 \mu \mathrm{m}$ at feed concentration $1.82 \mathrm{~kg} / \mathrm{m}^{3}$. 
feed concentration. In this study, the Central Composite Face-Centered CCF Response Surface Method (RSM) was selected as the experimental design method. Twenty experiments were performed and the fouling attachment probabilities ( $\alpha_{p p}$ and $\alpha_{p m}$ ) were calculated for each experimental run, as shown in Table 3. The results were analyzed using multiregression so as to identify the effects of the process parameters on the membrane fouling in ultrafiltration of a latex solution. Moreover, the process parameters were examined in order to identify the optimum conditions that would allow for the minimum fouling attachment probabilities. The analysis of the results indicated that the fouling attachment probabilities directly depend on the operating conditions being implemented. Depositional attachment probability $\alpha_{p m}$ and the coagulation fouling probabilities $\alpha_{p p}$ vary between the ranges of 0.3 to 0.98 and 0.15 to 0.95 , respectively. The mean value of the depositional attachment probability is 0.67 , while the mean value of the coagulation attachment probability is 0.58 .
Based on the ANOVA analysis, quadratic and linear models best fitted the experimental data for $\alpha_{p p}$ and $\alpha_{p m}$. The models for $\alpha_{p m}$ and $\alpha_{p p}$ are given in Equation (5) and Equation (6), respectively. In addition, the goodness of fit was determined by evaluating the coefficients of determination $\left(R^{2}\right)$. $R^{2}$ was $96 \%$ for the quadratic and linear models. In fact, $R^{2} 96 \%$ indicated that the models can adequately predict the relationships between the selected parameters.

$a_{p m}=1.014+0.008{ }^{*} A-0.051$ * $B-0.25962^{*} C$ (Eq. 5) $\alpha_{\mathrm{pp}}=-0.94833+0.043034^{\star} \mathrm{A}-0.000606061^{\star} \mathrm{B}+$ $1.21732^{*} \mathrm{C}+0.00125{ }^{*} \mathrm{~A}^{*} \mathrm{~B}-0.00240385^{*} \mathrm{~A}^{*} \mathrm{C}-$ $0.05609{ }^{*} B{ }^{*} C-0.000668182{ }^{*} A^{2}-0.000757576{ }^{*} B^{2}-$ $0.22862{ }^{*} C^{2}$

where fouling attachment probabilities are functions of transmembrane pressure $(A)$ [psi], feed flow rate $(B)$ [LPM], and feed concentration (C) $\left[\mathrm{kg} / \mathrm{m}^{3}\right]$. A positive sign implies that increasing the factor improves the effect and vice versa. The sign of the quadratic term

Table 3: Experimental Parameters and Results Based on the Experimental Design for the Fouling Attachment Probabilities

\begin{tabular}{|c|c|c|c|c|c|c|c|c|}
\hline \multirow[b]{2}{*}{$\begin{array}{l}\text { Exp } \\
\text { No. }\end{array}$} & \multicolumn{6}{|c|}{ Independent Variables } & \multirow[b]{2}{*}{$\begin{array}{c}\alpha_{p p} \\
\text { [dimensionless] }\end{array}$} & \multirow[b]{2}{*}{$\frac{\alpha_{p m}}{\text { [dimensionless] }}$} \\
\hline & $\begin{array}{l}\text { Pressure } \\
\text { P [psi] }\end{array}$ & $\begin{array}{l}\text { Coded } \\
\text { Factor } \\
\text { of } P\end{array}$ & $\begin{array}{c}\text { Feed } \\
\text { Flow rate } \\
Q \text { [LPM] }\end{array}$ & $\begin{array}{c}\text { Coded } \\
\text { Factor of } Q\end{array}$ & $\begin{array}{c}\text { Feed } \\
\text { Concentration } \\
C_{\mathrm{f}}\left[\mathrm{kg} / \mathrm{m}^{3}\right]\end{array}$ & $\begin{array}{c}\text { Coded } \\
\text { Factor of } C_{f}\end{array}$ & & \\
\hline 1 & 15 & -1 & 1 & -1 & 0.78 & -1 & 0.3 & 0.95 \\
\hline 2 & 35 & 1 & 1 & -1 & 0.78 & -1 & 0.5 & 0.98 \\
\hline 3 & 15 & -1 & 7 & 1 & 0.78 & -1 & 0.15 & 0.6 \\
\hline 4 & 35 & 1 & 7 & 1 & 0.78 & -1 & 0.4 & 0.73 \\
\hline 5 & 15 & -1 & 1 & -1 & 1.82 & 1 & 0.9 & 0.6 \\
\hline 6 & 35 & 1 & 1 & -1 & 1.82 & 1 & 0.95 & 0.79 \\
\hline 7 & 15 & -1 & 7 & 1 & 1.82 & 1 & 0.3 & 0.3 \\
\hline 8 & 35 & 1 & 7 & 1 & 1.82 & 1 & 0.6 & 0.5 \\
\hline 9 & 15 & -1 & 4 & 0 & 1.3 & 0 & 0.4 & 0.55 \\
\hline 10 & 35 & 1 & 4 & 0 & 1.3 & 0 & 0.75 & 0.8 \\
\hline 11 & 25 & 0 & 1 & -1 & 1.3 & 0 & 0.76 & 0.82 \\
\hline 12 & 25 & 0 & 7 & 1 & 1.3 & 0 & 0.51 & 0.48 \\
\hline 13 & 25 & 0 & 4 & 0 & 0.78 & -1 & 0.4 & 0.78 \\
\hline 14 & 25 & 0 & 4 & 0 & 1.82 & 1 & 0.76 & 0.5 \\
\hline 15 & 25 & 0 & 4 & 0 & 1.3 & 0 & 0.65 & 0.68 \\
\hline 16 & 25 & 0 & 4 & 0 & 1.3 & 0 & 0.64 & 0.69 \\
\hline 17 & 25 & 0 & 4 & 0 & 1.3 & 0 & 0.66 & 0.67 \\
\hline 18 & 25 & 0 & 4 & 0 & 1.3 & 0 & 0.64 & 0.67 \\
\hline 19 & 25 & 0 & 4 & 0 & 1.3 & 0 & 0.66 & 0.68 \\
\hline 20 & 25 & 0 & 4 & 0 & 1.3 & 0 & 0.65 & 0.68 \\
\hline
\end{tabular}


Table 4: Regression Coefficients and Probability Values of Statistical Analysis

\begin{tabular}{|c|c|c|c|c|c|}
\hline Coded Factor & Actual Factor & Coefficient for $\alpha_{p p}$ & $p$-value & Coefficient for $\alpha_{p m}$ & p-value \\
\hline A & Pressure & +0.043034 & $<0.0001$ & +0.008 & $<0.0001$ \\
\hline B & Feed Flow rate & -0.000606061 & $<0.0001$ & -0.051 & $<0.0001$ \\
\hline C & Feed Concentration & +1.21732 & $<0.0001$ & -0.25962 & $<0.0001$ \\
\hline$A * B$ & Pressure * Feed Flow rate & +0.00125 & 0.0231 & 0 & 0 \\
\hline$A^{*} C$ & $\begin{array}{l}\text { Pressure * Feed } \\
\text { Concentration }\end{array}$ & -0.00240385 & 0.3926 & 0 & 0 \\
\hline $\mathrm{B}^{\star} \mathrm{C}$ & $\begin{array}{l}\text { Feed Flow rate * Feed } \\
\text { Concentration }\end{array}$ & -0.05609 & $<0.0001$ & 0 & 0 \\
\hline$A^{2}$ & Pressure $^{2}$ & -0.000668182 & 0.0188 & 0 & 0 \\
\hline$B^{2}$ & Feed Flowrate ${ }^{2}$ & -0.000757576 & 0.7809 & 0 & 0 \\
\hline$C^{2}$ & Feed Concentration ${ }^{2}$ & -0.22862 & 0.0269 & 0 & 0 \\
\hline
\end{tabular}

Values of "p-value"less than 0.05 indicate model terms are significant. In this case of $\alpha_{p p}: A, B, C, A B, B C, A^{2}, C^{2}$ are significant model terms.

In the case of $\alpha_{p m}$ : $A, B, C$ are significant model terms.

coefficient indicates that the curve is concave downward when it has a negative sign and concave upward when it has a positive sign. To assess their validity the generated results were then analyzed by the ANOVA as presented in Table 4. The $p$-value is the probability value used to set the level of confidence for the F-test and to ascertain the significance of each of the coefficients. The $p$-value should be less than or equal to 0.05 to be significant $[16,17]$. According to regression coefficients and probability values ( $P$-value) shown in Table 4, the linear terms were all functionally significant for both fouling attachment probabilities. Thus it can be concluded from Equation (5) that in order to minimize the depositional attachment probability $\left(\alpha_{\mathrm{pm}}\right)$ the pressure should be decreased while the feed flow rate and feed concentration should be increased. The interactions of the transmembrane pressure-feed flow rate $(A B)$ and the feed flow ratefeed concentration (BC) are also significant for particleto-particle attachment $\left(\alpha_{\mathrm{pp}}\right)$. Indeed, higher particle-toparticle attachment was achieved at higher transmembrane pressure-feed flow rate interaction $(A B)$. On the other hand, at higher feed flow rate-feed concentration interaction (BC) the coagulation attachment was decreased.

Fouling attachment probabilities estimated from the generated models in Equation 5 \& 6 were then compared to the actual values of attachment probabilites $\left(\alpha_{p p}\right.$ and $\left.\alpha_{p m}\right)$. This validation to ascertain the reliability and accuracy of the generated models at a range of process parameters. The actual values of fouling attachemnt probabilities calculated from Equations 1 \& 2 using the exprimental values of $m_{c} \&$ $m_{p}$ for each ultrafiltration run same operating conditions. Figure 11 indicates a good agreement of the predicted values of attachemnt probabilities $\left(\alpha_{p p}\right.$ and $\alpha_{\mathrm{pm}}$ ) and the actual values.

Moreover, additional expriments were performed with process parameters outside of the original range used in the RSM exprimental design. In these experiments, the fouling attachment probabilities $\alpha_{p p}$ and $\alpha_{\mathrm{pm}}$ were calculated using Equations (1) and (2) and then compared to $\alpha_{p p}$ and $\alpha_{p m}$ predicted using Equations (5) and (6). Table 5 presents a good agreement between fouling attachments predicted from regression correlations with actual values at different operating conditions. Depositional attachment probability predicted using Equation (5) is within 2 - 4 $\%$ error of the actual values. However, the coagulation attachment probability predicted from Equation (6) is within 0 - $9 \%$ error of actual values.

The process parameters were then analyzed to identify the optimum conditions for a minimum fouling probability within the range of process parameters implemented in this study. For the depositional attachment $\alpha_{p m}$, the minimum value achieved is 0.2961 at $16.32 \mathrm{psi}, 6.88 \mathrm{LPM}$ and $1.78 \mathrm{~kg} / \mathrm{m}^{3}$. The minimum value of 0.134 for particle-to-particle attachment (coagulation potential) was achieved at 15.33 psi, 6.87 LPM and $0.8 \mathrm{~kg} / \mathrm{m}^{3}$. These optimal conditions indicated that the minimum response of both fouling attachment probabilities could be obtained at the minimum transmembrane pressure, medium feed concentration, and maximum feed flow rate of the range of process parameters used in the present study. 


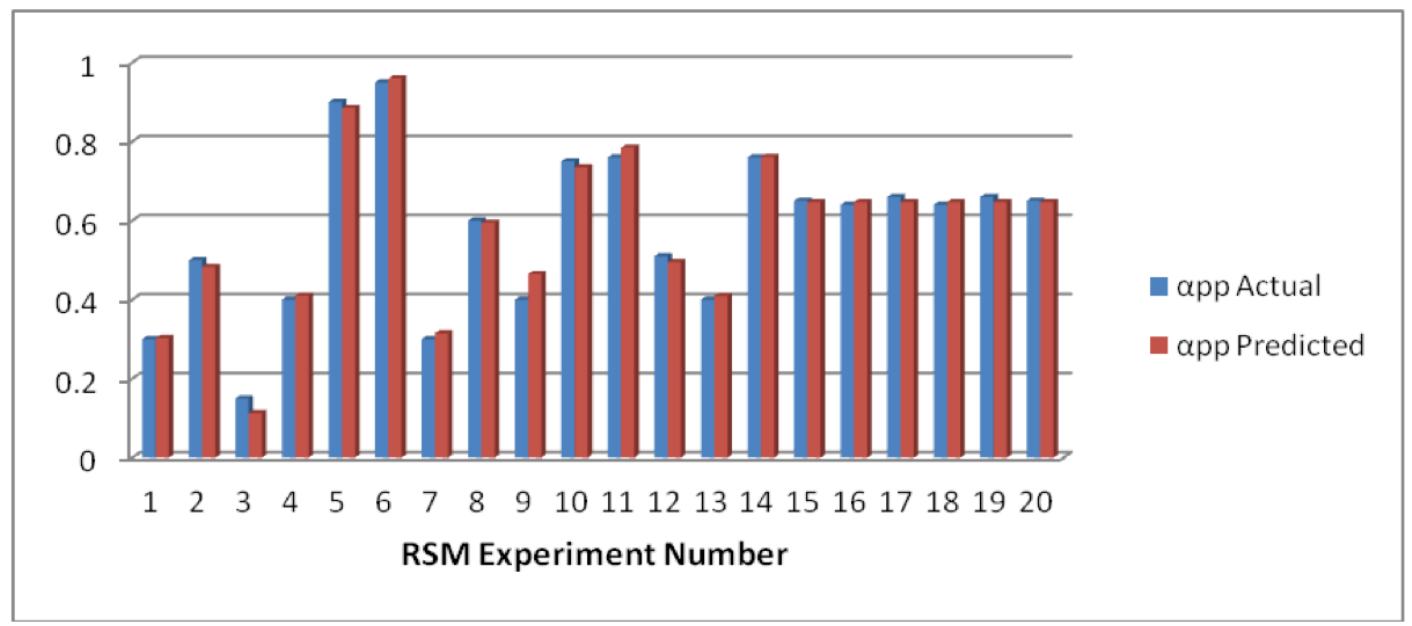

(a)

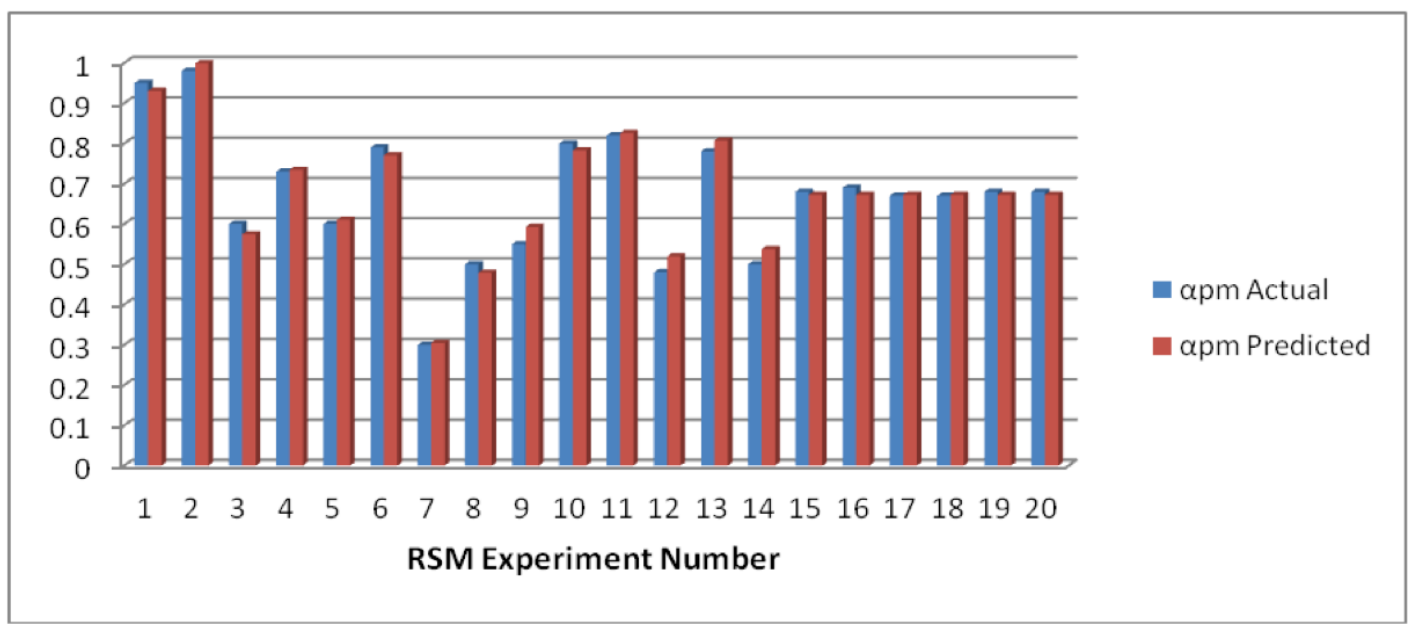

(b)

Figure 11: Actaual and predicted fouling attachment probabilities agreement. (a) Coagulation attachment probability ( $\left.\alpha_{\mathrm{pp}}\right)$. (b) Depositional attachment probability $\left(\alpha_{\mathrm{pm}}\right)$.

Table 5: Agreement of Fouling Attachments Prediction from Regression Correlations with Actual Values for Extra Experiments Out of the Range of Process Parameters

\begin{tabular}{|c|c|c|c|c|c|c|c|c|}
\hline$P$ [psi] & $Q$ [LPM] & $C_{f}\left[\mathrm{~kg} / \mathrm{m}^{3}\right]$ & $\alpha_{p p}$ & $\alpha_{p m}$ & $\alpha_{p p}$ Predicted & $\alpha_{p m}$ Predicted & $\%$ Error $\left[\alpha_{p p}\right]$ & $\% \operatorname{Error}\left[\alpha_{\mathrm{pm}}\right]$ \\
\hline 40 & 4 & 1.3 & 0.76 & 0.81 & 0.67 & 0.79 & -7.9 & -2.2 \\
\hline 45 & 4 & 1.3 & 0.76 & 0.8 & 0.61 & 0.83 & -9.2 & 4.1 \\
\hline
\end{tabular}

$\alpha_{p p}$ and $\alpha_{p m}$ were calculated using Equation (1) and (2) and the experimental values of $m_{p}$ and $m_{c}$. $\alpha_{\mathrm{pp}}$ and $\alpha_{\mathrm{pm}}$ predicted using Equations (5) and (6).

Error $=[(\text { Estimated value }- \text { Actual value }) / \text { Actual value }]^{\star} 100$

\section{CONCLUSION}

According to the results obtained in the present study, it was observed that higher fouling probabilities brought about an increase in the total mass of the fouling retained by the membrane and the cake layer height, which in turn resulted in an increased resistance to the permeate flux. At a feed flow rate of $4.0 \mathrm{~L} / \mathrm{min}$ and a feed concentration of $1.3 \mathrm{~kg} / \mathrm{m} 3$, increases in the transmembrane pressure from 15 to 45 psi caused the particle-to-particle attachment to 
increase from 0.4 to 0.76 and the particle-to-membrane attachment to raise from 0.55 to 0.81 . The mass of the fouling was also increased correspondingly from $0.0104 \mathrm{~kg} / \mathrm{m}^{2}$ to $0.0145 \mathrm{~kg} / \mathrm{m}^{2}$.

At a higher feed flow rate of 6 LPM, both attachment fouling probabilities decreased, causing the decrease in the mass of particles retained by the membrane from $0.0162 \mathrm{~kg} / \mathrm{m}^{2}$ at $1 \mathrm{LPM}$ to $0.0084 \mathrm{~kg} / \mathrm{m}^{2}$ at $6 \mathrm{LPM}$. The coagulation attachment probability $\left(\alpha_{\mathrm{pp}}\right)$ had a more significant reduction from 0.86 at 1 LPM to 0.19 at 6 LPM as compared with the deposition attachment probability $\left(\alpha_{\mathrm{pm}}\right)$. In addition, increasing the feed concentration from $0.78 \mathrm{~kg} / \mathrm{m}^{3}$ to $1.82 \mathrm{~kg} / \mathrm{m}^{3}$ resulted in a substantial increase in the coagulation attachment probability from 0.3 to 0.9 while the particle-tomembrane attachment probability decreased from 0.95 to 0.6 . The total mass of fouling increased from 0.0088 $\mathrm{kg} / \mathrm{m}^{2}$ to $0.0133 \mathrm{~kg} / \mathrm{m}^{2}$ and the cake height raised from $4.3 \mu \mathrm{m}$ to $18.5 \mu \mathrm{m}$.

The data obtained from experiments designed by the RSM were fitted to non-linear and linear models using multi-variable regression. Quadratic and linear models best fitted the experimental data for $\alpha_{p p}$ and $\alpha_{p m}$, respectively. The lowest attachment probabilities were obtained at the minimum transmembrane pressure, the medium feed concentration, and the maximum feed flow rate in the ranges of process parameters used in the present study. Low mass of fouling and high volumetric permeate flux were also obtained at the lowest attachment probabilities. Moreover, this study demonstrated that the particle-to-particle attachment probability was the predominant factor responsible for the cake formation, even though the particle-tomembrane attachment $\left(\alpha_{\mathrm{pm}}\right)$ decreased alongside the increasing feed concentration.

\section{ACKNOWLEDGMENTS}

The authors are grateful for the financial support from Natural Science and Engineering Research Council of Canada (NSERC). The assistance and facilities provided by the Department of Chemical Engineering, Ryerson University, are also highly appreciated.

\section{NOMENCLATURE}

\section{Symbol Description}

$C_{\text {in }}$

$\mathrm{C}_{\mathrm{f}}$

D

$D_{m}$

$L_{m}$

$m_{p}$

$m_{c}$

$m_{t}$

$N_{m}$

P-value

Q

$\mathrm{R}^{2}$

$V_{s}$

$X_{i}$

Y

$\sigma$

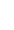

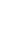

(1)

$\sigma_{L}$

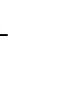



$\sigma_{S} \quad$ projected area of a unit mass of the small particles on membrane surface $\left[\mathrm{m}^{2} / \mathrm{kg}\right]$ (pore diameter $/ 6<$ particle size $<$ pore diameter/2)

$\sigma_{\mathrm{xS}}$

projected area of a unit mass of the very small particles on membrane surface $\left[\mathrm{m}^{2} / \mathrm{kg}\right.$ ] (particle size < pore diameter/6)

$\varepsilon_{\mathrm{s}} \quad \begin{aligned} & \text { membrane surface porosity } \\ & \text { [dimensionless] }\end{aligned}$

$\alpha_{\mathrm{pm}}$

The attachment probabilities between a particle and the membrane [dimensionless]

$\alpha_{p p}$

The attachment probabilities between two particles [dimensionless]

\section{REFERENCES}

[1] Dey BK, Hashim MA, Hasan S, Gupta BS. Microfiltration of water-based paint effluents. Adv Environ Res 2004; 8(3-4): 455-66. http://dx.doi.org/10.1016/S1093-0191(02)00122-3

[2] Körbahti B, Aktaş N, Tanyolaç A. Optimization of electrochemical treatment of industrial paint wastewater with response surface methodology. J Hazardous Mater 2007; 148(1-2): 83-90. http://dx.doi.org/10.1016/.j.jhazmat.2007.02.005

[3] Kurt U, Avsar Y, Gonullu MT. Treatability of water-based paint wastewater with Fenton process in different reactor types. Chemosphere 2006; 64(9): 1536-40. http://dx.doi.org/10.1016/j.chemosphere.2005.11.026

[4] Kennedy M, Kamanyi J, Rodriguez S, Lee N, Schippers J, Amy G. Water Treatment by microfiltration and ultrafiltration. Adv Membr Technol Appl 2008; 131-70.

[5] Javacek $\mathrm{MH}$, Bouchet F. Constant flow rate blocking laws and an example of their application to dead-end microfiltration of protein solutions. J Membr Sci 1993; 82: 285-95.

http://dx.doi.org/10.1016/0376-7388(93)85193-Z
[6] Kosvintsev S, Cumming IW, Holdich RG, Lloyd D, Starov VM. Sieve mechanism of microfiltration separation. Colloids and Surfaces: Physicochem Eng Aspects 2004; 230: 167-82. http://dx.doi.org/10.1016/j.colsurfa.2003.09.027

[7] Al-Amoudi A, Lovitt RW. Fouling strategies and the cleaning system of NF membranes and factors affecting cleaning efficiency. J Membr Sci 2007; 303: 4-28. http://dx.doi.org/10.1016/j.memsci.2007.06.002

[8] Avlonitis SA, Kouroumbas K, Vlachakis N. Energy consumption and membrane replacement cost for seawater RO desalination plant. Desalination 2003; 157: 151-58. http://dx.doi.org/10.1016/S0011-9164(03)00395-3

[9] Huang $\mathrm{H}$, Young TA, Jacangelo JG. Unified membrane fouling index for low pressure membrane filtration of natura waters: principles and methodology. Environ Sci Technol 2008; 42: 714-20.

http://dx.doi.org/10.1021/es071043j

[10] Viadero RC, Vaughan RL, Reed JBE. Study of series resistances in high-shear rotary ultrafiltration. J Membr Sci 1999;162: 199-11. http://dx.doi.org/10.1016/S0376-7388(99)00143-X

[11] Bruijn JPF, Salazar FN, Borquez R. Membrane blocking in ultrafiltration, a new approach to fouling. Inst Che Eng 2005: 83: 211-19.

[12] Song L. Flux decline in crossflow microfiltration and ultrafiltration: mechanism and modelling of membrane fouling. J Membr Sci1998; 139: 183-200. http://dx.doi.org/10.1016/S0376-7388(97)00263-9

[13] Paris J, Guichardon P, Charbit F. Transport phenomena in ultrafiltration: a new two-dimensional model compared with classical models. J Membr Sci 2002; 207: 43-58. http://dx.doi.org/10.1016/S0376-7388(01)00752-9

[14] Abdelrasoul A, Doan H, Lohi A. A Mechanistic Model for Ultrafiltration Membrane Fouling by Latex. J Membr Sci 2013; 433: 88-99. http://dx.doi.org/10.1016/j.memsci.2013.01.003

[15] Montgomery DC. Design and Analysis of Experiment. Fifth edition, Wiley, Inc., New York, USA 1997.

[16] Yuliwati E, Ismail AF, Lau WJ, Ng BC, Mataram A, Kassim MA. Effects of process conditions in submerged ultrafiltration for refinery wastewater treatment: Optimization of operating process by response surface methodology. Desalination 2012; 287: 350-61. http://dx.doi.org/10.1016/j.desal.2011.08.051

[17] Calatayud M, Vela M, Blanco S, García J, Rodríguez E. Analysis and optimization of the influence of operating conditions in the ultrafiltration of macromolecules using a response surface methodological Approach. Chem Eng J 2010; 156: 337-46 http://dx.doi.org/10.1016/j.cej.2009.10.031 